.

\title{
Discriminação alélica em ovinos naturalizados do Pantanal Sul-Matogrossense por meio de marcadores microssatélites
}

\section{Allelic discrimination in naturalized ovine from Pantanal Sul-Matogrossense by means of microsatellite markers}

\author{
Crispim, Bruno do Amaral ${ }^{1}$; Silva, Danielly Beraldo dos Santo ${ }^{1}$; Banari, Alexandre Campos ${ }^{1}$; Seno, Leonardo de \\ Oliveira $^{1}$; Grisolia, Alexéia Barufatti ${ }^{1}$
}

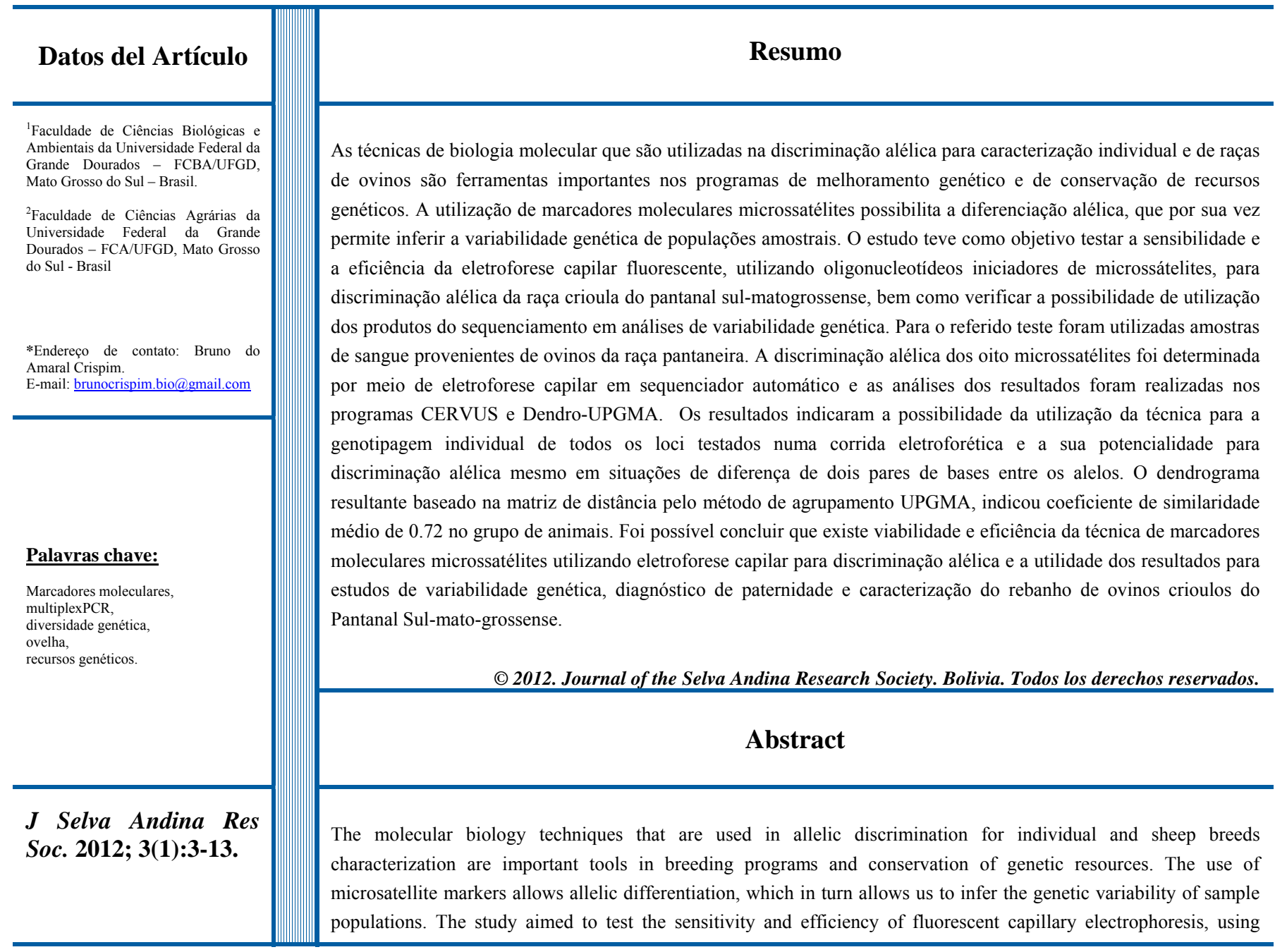




\begin{tabular}{|c|c|}
\hline $\begin{array}{l}\text { Historial del artículo } \\
\text { Recibido Abril, } 2012 . \\
\text { Devuelto Junio } 2012 \\
\text { Aceptado Julio, 2012. } \\
\text { Disponible en linea, Agosto, } 2012 . \\
\end{array}$ & $\begin{array}{l}\text { microsatellite primers, for allelic discrimination of the Crioulo breed from Pantanal sul-matogrossense, as well as } \\
\text { verify the possibility of using the products of sequencing in genetic variability analysis. For this test, were used blood } \\
\text { samples from Pantaneira breed sheep. The allelic discrimination of eight microsatellites was determined by capillary } \\
\text { electrophoresis in automatic sequencer and the results analyses were performed on the programs CERVUS and } \\
\text { Dendro-UPGMA. The results indicated the possibility of using this technique for the individual genotyping of all loci }\end{array}$ \\
\hline $\begin{array}{l}\text { Key words: } \\
\text { Molecular markers, } \\
\text { multiplex PCR, } \\
\text { genetic diversity, } \\
\text { sheep, } \\
\text { genetic resources. }\end{array}$ & $\begin{array}{l}\text { tested in electrophoretic analysis and its potential to allelic discrimination even in case of difference between two } \\
\text { pairs of bases between the alleles. The resulting dendrogram based on the distance matrix by the UPGMA assembly } \\
\text { method, indicated medium similarity coefficient of } 0.72 \text { in the group of animals. It was concluded that there is the } \\
\text { viability and efficiency of the microsatellite molecular markers technique using capillary electrophoresis for allelic } \\
\text { discrimination and the utility of results for studies of genetic variability, paternity diagnosis and characterization of }\end{array}$ \\
\hline $\begin{array}{l}\text { Editado por: } \\
\text { "Selva Andina } \\
\text { Research } \\
\text { Society" }\end{array}$ & (c) 2012. Journal of the Selva Andina Research Society. Bolivian. All rights reserved. \\
\hline
\end{tabular}

\section{Introdução}

Os microssatélites são marcadores moleculares que apresentam alta sensibilidade, elevada capacidade de discriminação entre indivíduos, alto polimorfismo, heterozigose elevada e praticidade em rotinas laboratoriais. Estas características importantes tornaram este marcador útil para a realização de testes de parentesco, genética forense, caracterização e análise de diversidade genética (Gao et al 2007, Arranz et al 2001). A escolha correta dos microssatélites permite a elaboração de sistemas multiplex para a amplificação simultânea de diversos loci ao mesmo tempo, acelerando assim os procedimentos laboratoriais, facilitando a discriminação alélica e possibilitando a análise de amostras que possuem baixa concentração de DNA (Beaumont \& Bruford 1999).

A visualização das sequências amplificadas dos microssatélites pode ser feita por meio de três matrizes sólidas: eletroforese em gel de agarose ou em gel de poliacrilamida desnaturante ou não desnaturante e sequenciamento automático (Ferreira \& Grattapaglia 1998). A escolha do tipo de gel está relacionada ao tamanho do fragmento e diferença de tamanho dos fragmentos de DNA.

Atualmente, têm-se realizado PCRs multiplex que utilizam primers marcados com corantes fluorescentes, tais como HEX, TET e FAM. Essas reações são aplicadas no interior de um capilar, e a migração do DNA acontece até passar pelo leitor do sequenciamento automático. Um feixe de laser rastreia o gel, excitando os marcadores, que emitem luzes em um comprimento de onda específico, de acordo com o corante utilizado. A luz é detectada e o padrão do espectro analisado com ajuda de programas específicos para cada sequenciador que permitem ler as sequências de DNA (Voet et al 2002). Os resultados da genotipagem automatizada baseada em fluorescência são mais informativos, pois permite a detecção de vários produtos amplificados de forma simultânea, o que diminui o custo das análises e o tempo de leitura por amostra (Kashyap et al 2004). 
A corrida eletroforética dos produtos amplificados leva aproximadamente 30 minutos e os fragmentos são separados de acordo com o número de pares de bases e a cor do flurocromo. A separação dos alelos por meio dessa tecnologia detecta a fluorescência induzida por laser e dispensa o uso de placas de géis (Tang \& To 2006).

Para mover as moléculas da amostra através do polímero presente no capilar, necessita-se aplicar uma voltagem específica para cada reação por um determinado tempo. As moléculas de DNA que possuem peso molecular menor se deslocam mais rápido que as moléculas maiores. Quando os fragmentos de DNA alcançam a janela de detecção, as moléculas marcadas com fluoróforo são excitadas pelo laser, emitindo fluorescência no momento em que os fragmentos passam e uma câmera coleta as intensidades da emissão de quatro diferentes comprimentos de onda. As emissões são espectralmente separadas pelo espectrógrafo reflexivo. Um padrão interno, contendo fragmentos de DNA de tamanho conhecido e marcado com corante diferente também é processado junto sendo utilizado como controle (Fig 1). Os dados coletados são convertidos em electroferogramas e que podem ser visualizados e analisados por meio de softwares específicos de acordo com o sequenciador utilizado (Tang \& To 2006).

Além da possibilidade de automação e da utilização de PCR multiplex, a detecção dos marcadores microssatélites por eletroforese capilar em sequenciador automático permite distinguir com facilidade alelos que variam em uma única unidade repetitiva, o que aumenta a precisão dos dados moleculares obtidos e a reprodutibilidade dos resultados. Nesse contexto, objetivou-se nesse estudo demonstrar a sensibilidade e eficiência da técnica de eletroforese capilar, e demonstrar a sua potencialidade em análise de variabilidade genética da raça crioula do Pantanal SulMatogrossense.

Fig 1 Esquema das etapas de funcionamento da Eletroforese Capilar em Sequenciador Automático

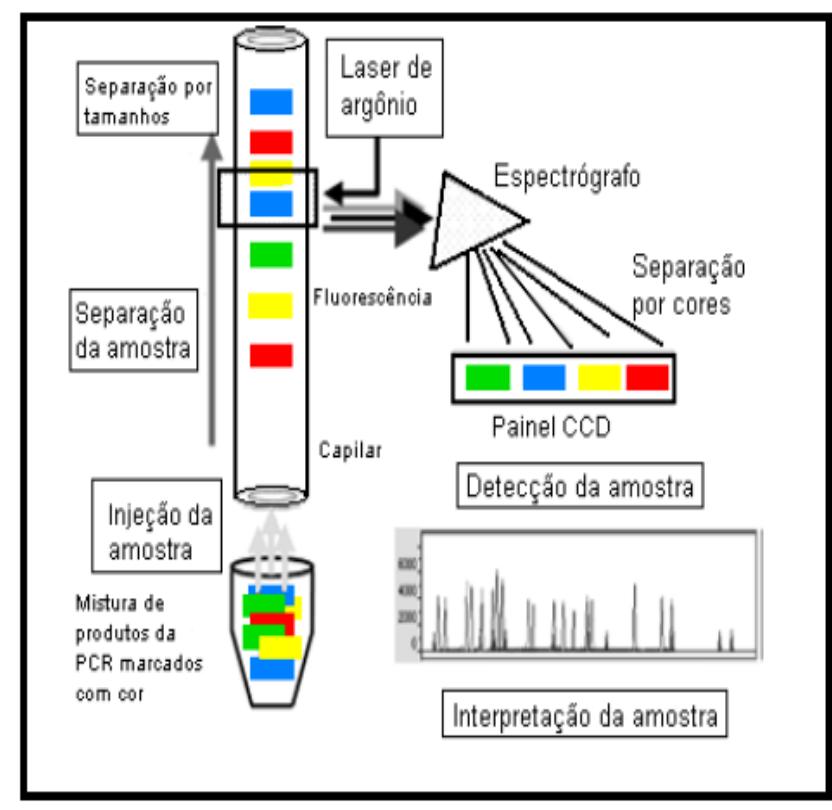

Adaptado de Pena (2010).

\section{Materiales e métodos}

No estudo, foram utilizadas amostras de dez ovinos crioulos do Pantanal (SRD, sem raça definida), que também é conhecida como "Pantaneira Sul-Matogrossense". Os animais pertencem ao rebanho da Fazenda Experimental da Universidade Federal da Grande Dourados (FAECA/UFGD), localizada no município de Dourados, MS. As amostras de sangue foram 
coletadas por punção da veia jugular em tubos para coleta de sangue (Vaccutainer ${ }^{\circledR}$ ) de $4.5 \mathrm{~mL}$, contendo anticoagulante K3 EDTA. As amostras foram mantidas sob-refrigeração até a realização da extração do DNA.

A extração de DNA foi realizada a partir de $300 \mu \mathrm{L}$ de sangue. As amostras de sangue foram colocadas em microtubos a esse material foi adicionado $2 \mu \mathrm{L}$ de Proteinase $\mathrm{K}(20 \mathrm{mg} / \mathrm{mL})$ e $500 \mu \mathrm{L}$ de SDS (Sodecil Sulfato de Sódio) a 20\%. A homogeneização do material foi realizada em vortex e para incubação utilizou-se banho-maria a $60^{\circ} \mathrm{C}$ por 1 hora e 30 minutos. Em seguida, foram adicionados $800 \mu \mathrm{L}$ de clorofórmio e acrescentados $350 \mu \mathrm{L}$ de solução de precipitação (3M acetato de potássio, 6.6M ácido acético glacial). $\mathrm{O}$ material foi centrifugado a $18.000 \mathrm{x} g$ por 10 minutos a $4^{\circ} \mathrm{C}$. A fase aquosa foi aliquotada e transferida para outro microtubo.

Posteriormente, foi adicionado $1 \mathrm{~mL}$ de etanol $100 \%$ gelado em cada microtubo e homogeneizado por inversão. $\mathrm{O}$ conteúdo foi centrifugado novamente a 18.000 x g por 5 minutos a $4^{\circ} \mathrm{C}$ e em seguida o sobrenadante foi desprezado e adicionou-se $1 \mathrm{~mL}$ de etanol $70 \%$. Novamente cada microtubo foi centrifugado e o sobrenadante desprezado e os microtubos foram invertidos para secagem. Ao final do procedimento o precipitado foi eluído em $100 \mu \mathrm{L}$ de TE (10 mM Tris HCl, 1mM EDTA) pH 8.7 com RNase (Promega) $1 \mu \mathrm{g} / \mathrm{mL}$.

A qualidade do DNA foi observada por meio de eletroforese em gel de agarose corada com brometo de etídeo, Além disso, dados referentes à quantidade de DNA (ng/ $/ \mathrm{L}$ ) e qualidade (razão de 260/280 nm) foram obtidos por meio de espectrofotometria $\left(\right.$ Nanodrop $\left.^{\circledR}\right)$. O DNA foi submetido à Reação em Cadeia pela Polimerase Multiplex (mPCR). Para tanto, foram utilizados oito pares de oligonucleotídeos iniciadores específicos que flanqueiam regiões de microssatélites aleatórias.

A seleção dos primers foi baseada em listas de marcadores microssatélites para ovinos, que são disponibilizadas pela FAO 2011. As reações mPCR e sequenciamento foram realizadas em termociclador de temperatura programável (Termocicler VeriFlex 384, Applied Biosystems).

As reações com volume final de $10 \mu 1$ foram preparadas contendo: $3.6 \mu \mathrm{l}$ de água ultra-pura q.s.p., $1.5 \mu 1$ de Tampão, mix de $1.5 \mu 1$ de primers (CSRD 0247, HSC, OarAE 129, MAF 214, OarFCB 304, OarCP 49, SPS 113, D5S2) descritos na Tabela $1,0.4 \mu \mathrm{l}$ de Taq DNA Polimerase (2 unidades) e 10 a 50ng de DNA genômico. As reações multiplex foram conduzidas contendo os oito pares de oligonucleotídeos iniciadores sendo que estes se diferenciam pelo tamanho de alelos que cada par de oligonucleotídeo iniciador amplifica (Kevorkian et al 2009). As sequencias Foward foram marcadas pelos corantes fluorescentes, HEX (6-carboxy$2^{\prime}, 4^{\prime} 7^{\prime}, 4,7$-hexaclorofluoresceina), FAM (6carboxifluoresceina), ou TET $\left(4,7,2^{\prime}, 7^{\prime}\right.$-tetracloro6-carboxifluoresceina).

Os ciclos de temperatura e condições para a amplificação foram constituídas de um passo inicial de desnaturação a $95^{\circ} \mathrm{C}$ por 7 minutos, 40 ciclos com desnaturação de $95^{\circ} \mathrm{C}$ por 30 segundos, 
anelamento a $63^{\circ} \mathrm{C}$ por 90 segundos e extensão a $72^{\circ} \mathrm{C}$ por 60 segundos. Ao final dos 40 ciclos realizou-se uma extensão final a $72^{\circ} \mathrm{C}$ por 30 minutos. Ao término do processo de amplificação, as amostras foram resfriadas a $4^{\circ} \mathrm{C}$. Em todos os experimentos foram realizados controles negativos contendo todos os reagentes exceto DNA, com o intuito de monitorar possíveis contaminações por DNA.

$\mathrm{Na}$ Tabela 1 foram representados os dados referentes ao tamanho dos fragmentos (pares de bases), oligonucleotideos iniciadores (Foward e Reverse) e seus respectivos marcadores fluorescentes. Após a mPCR, as regiões amplificadas foram submetidas à corrida eletroforéticas no equipamento $\mathrm{MegaBACE}^{\mathrm{TM}}$ 1000 DNA Analysis Systems (GE Healthcare, USA). Para tanto, foi preparada uma solução com TWEEN e marcador de peso molecular ET-400 (GE Healthcare). Em cada amostra foram colocados $0.3 \mu 1$ do marcador ROX, $7.7 \mu 1$ de TWEEN $0.02 \mathrm{X}$ e $2 \mu 1$ do produto de PCR. A placa contendo os reagentes foi desnaturada por 3 minutos a $94^{\circ} \mathrm{C}$ e colocada diretamente no gelo. A injeção das amostras foi feita a $3 \mathrm{KV}$ por 80 segundos e a corrida a $8 \mathrm{KV}$ por 80 minutos no MegaBACE $^{\mathrm{TM}} 1000$.

Tabela 1 Locus de microssatélite, localização no cromossomo (Crom), oligonucleotídeos iniciadores, marcadores fluorescentes e tamanhos dos fragmentos amplificados em pares de bases (pb) pela mPCR

\begin{tabular}{|c|c|c|c|c|c|}
\hline Locus & $\begin{array}{l}\text { Número } \\
\text { de Acesso }\end{array}$ & Crom & $\begin{array}{c}\text { Oligonucleotídeos } \\
\text { Foward (5'- 3') e marcadores } \\
\text { fluorescentes }\end{array}$ & $\begin{array}{l}\text { Oligonucleotídeos } \\
\text { Reverse (5’- 3’) }\end{array}$ & $\begin{array}{c}\text { Tamanho dos } \\
\text { fragmentos } \\
\text { (pb) }\end{array}$ \\
\hline CSRD247 & EU009450 & OAR 14 & $\begin{array}{c}\text { GGACTTGCCAGAACTCTGCAAT } \\
\text { (HEX - amarelo) }\end{array}$ & CACTGTGGTTTGTATTAGTCAGG & $208-250$ \\
\hline HSC & M90759 & OAR 20 & $\begin{array}{l}\text { CTGCCAATGCAGAGACACAAGA } \\
\text { (FAM - azul) }\end{array}$ & GTCTGTCTCCTGTCTTGTCATC & $270-306$ \\
\hline OarAE129 & L11051 & OAR 5 & $\begin{array}{l}\text { AATCCAGTGTGTGAAAGACTAATCCAG } \\
\text { (TET - verde) }\end{array}$ & $\begin{array}{l}\text { GTAGATCAAGATATAGAATATTTTTCA } \\
\text { ACACC }\end{array}$ & $135-165$ \\
\hline MAF214 & M88160 & OAR 16 & $\begin{array}{c}\text { AATGCAGGAGATCTGAGGCAGGGACG } \\
\text { (TET - verde) }\end{array}$ & GGGTGATCTTAGGGAGGTTTTGGAGG & $181-256$ \\
\hline OarFCB 304 & L01535 & OAR 19 & $\begin{array}{l}\text { CCCTAGGAGCTTTCAATAAAGAATCGG } \\
\text { (HEX - amarelo) }\end{array}$ & CGCTGCTGTCAACTGGGTCAGGG & $148-190$ \\
\hline OarCP49 & U15702 & OAR 17 & $\begin{array}{l}\text { CAGACACGGCTTAGCAACTAAACGC } \\
\text { (HEX - amarelo) }\end{array}$ & GTGGGGATGAATATTCCTTCATAAGG & $77-103$ \\
\hline SPS113 & $\ldots$ & BTA 10 & $\begin{array}{l}\text { CCTCCACACAGGCTTCTCTGACTT } \\
\text { (FAM - azul) }\end{array}$ & CCTAACTTGCTTGAGTTATTGCCC & $138-150$ \\
\hline D5S2 & Z14040 & OAR 5 & $\begin{array}{l}\text { TACTCGTAGGGCAGGCTGCCTG } \\
\text { (FAM - azul) }\end{array}$ & GAGACCTCAGGGTTGGTGATCAG & $190-210$ \\
\hline
\end{tabular}


Os resultados gerados foram analisados no software Fragment Profiler version $1.2^{\circledR}$ (GE Healthcare). E, a sua possibilidade de aplicação em análises genéticas foi avaliada com o auxílio dos programas CERVUS ${ }^{\circledR}$ (Marshall et al 1998) e Dendro-UPGMA $^{\circledR} \quad$ (Unweighted Pair Group Method with Arithmetic mean) (Garcia-Vallvé \& Puigbo 2009). O primeiro fornece dados referentes ao número de alelos, a heterozigosidade esperada (He) e heterozigosidade observada (Ho) e o conteúdo de informação polimórfica (PIC). O segundo possibilita a construção de matriz de distância e fornece dados relativos a distância genética a partir da construção do dendograma por meio do método da UPGMA (unweitghted pairgroup method with arithmetical averages).

\section{Resultados}

Os resultados obtidos pela eletroforese capilar realizada em sequenciador automático da $\mathrm{mPCR}$ dos ovinos foram visualizados no programa Fragment Profiler version $1.2^{\circledR}$ (GE Healthcare). Esse programa gerou gráficos que foram demonstrados na Fig 2. O eixo $\mathrm{X}$ representa o tamanho dos fragmentos em pares de bases e o eixo $\mathrm{Y}$ indica a intensidade de fluorescência. Portanto, a partir de interpretação do gráfico foi possível determinar se o indivíduo genotipado foi homozigoto ou heterozigoto para determinado marcador. No exemplo da Fig 2, foram indicados os resultados da genotipagem para o marcadores OarAE129 em 3 indivíduos.

Os resultados obtidos pela eletroforese capilar realizada em sequenciador automático da $\mathrm{mPCR}$ dos ovinos foram visualizados no programa Fragment Profiler version 1.2 (GE Healthcare). Esse programa gerou gráficos que foram demonstrados na Figura 2. O eixo $\mathrm{X}$ representa o tamanho dos fragmentos em pares de bases e o eixo $\mathrm{Y}$ indica a intensidade de fluorescência. Portanto, a partir de interpretação do gráfico foi possível determinar se o indivíduo genotipado foi homozigoto ou heterozigoto para determinado marcador. No exemplo da Figura 2, foram indicados os resultados da genotipagem para o marcadores OarAE129 em 3 indivíduos.

Fig 2 Exemplo dos tamanhos dos alelos resultantes da PCR do microssatélite OarAE129 visualizados por electroforectrogramas no programa Fragment Profiler version 1.2 (GE Healthcare). (a) heterozigoto (148/150 pb); (b) heterozigoto (137/150 pb) e (c) homozigoto (148/148 pb) dos indivíduos 1, 3 e 9 respectivamente.
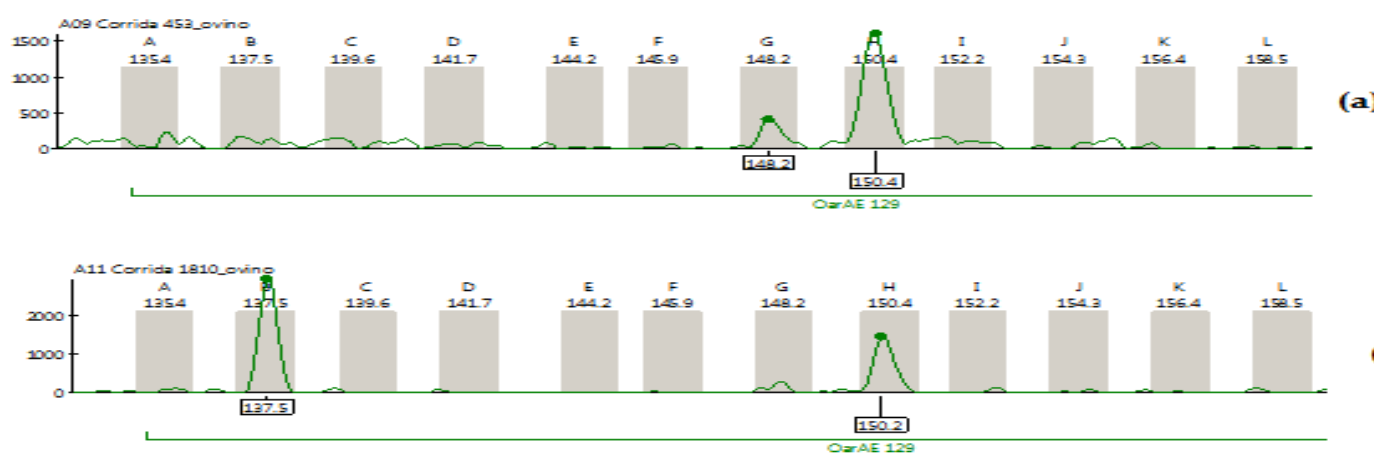

(b)

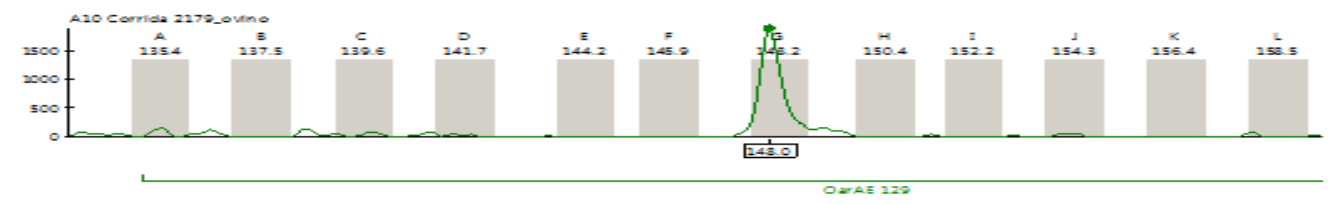


Os oito loci de microssatélites da mPCR foram discriminados e visualizados como demonstrados na Fig 3 para o animal número 4. Para os marcadores CSRD0247, D5S2, SPS113, MAF214, OarCP49, HSC, OarAE129, OarFCB304 foi possível identificar, respectivamente, os alelos 232/234, 192/192, 138/146, 192/233, 85/100, $276 / 290,148 / 150$ e $165 / 172$.

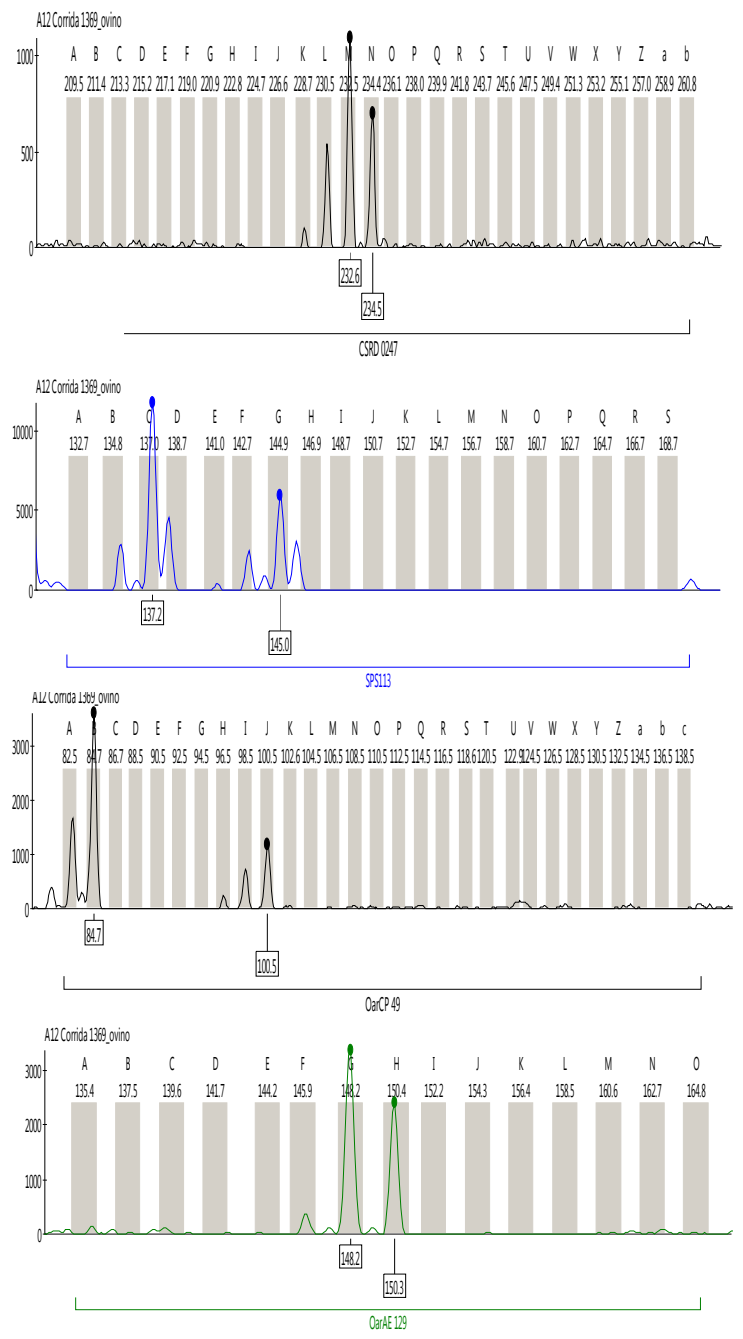

Esses resultados demonstram que a eletroforese possibilitou genotipar individualmente todos os loci testados para um indivíduo numa únic a amostra.
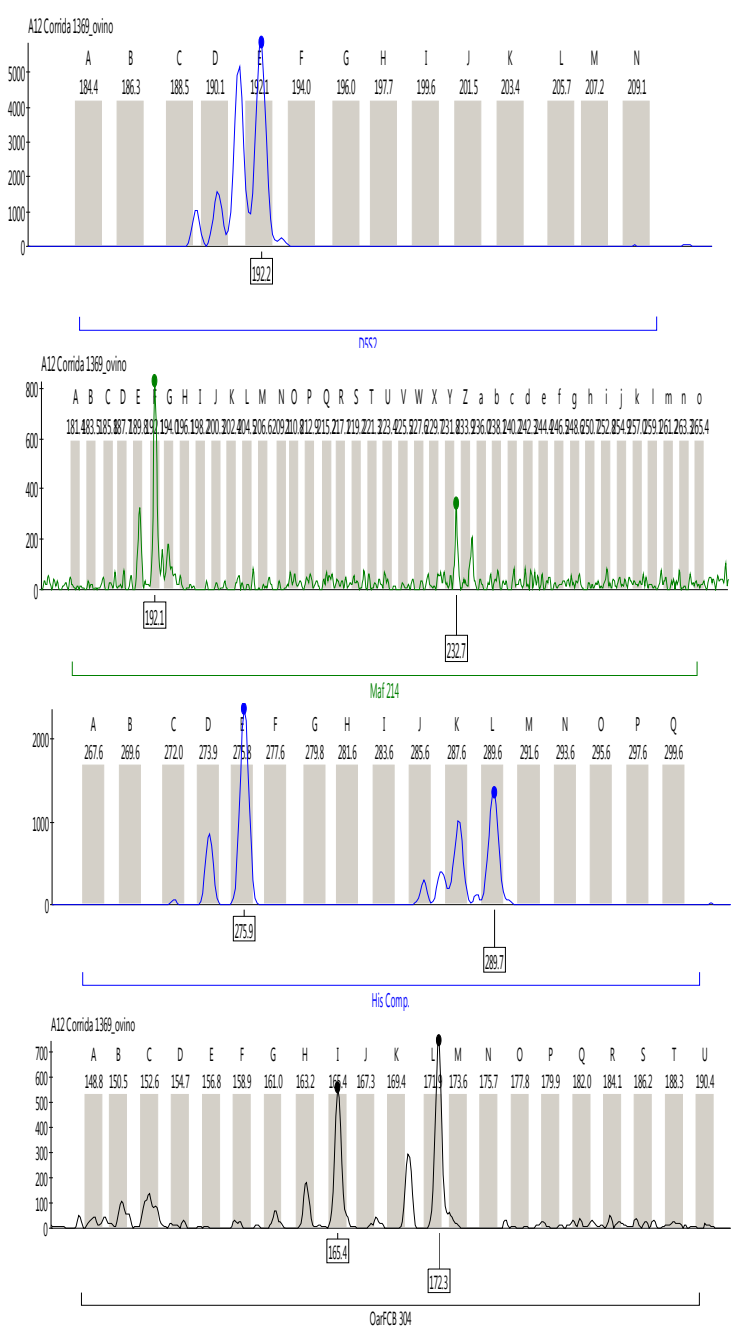

Fig 3 Electroforectrograma dos resultados referentes aos oito loci marcadores microssatélites (CSRD0247, D5S2, SPS113, MAF214, OarCP49, HSC, OarAE129, OarFCB304) do animal número 4 gerados no programa Fragment Profiler version 1.2 (GE Healthcare). 
A partir dos resultados gerados pelo eletroforectrograma foi possível determinar os alelos para cada um desses oitos loci de cada um dos indivíduos. As discriminações alélicas dos marcadores foram demonstradas na Tabela 2.

Tabela 2 Resultados referentes à eletroforese capilar da mPCR dos oito loci de marcadores microssatélites quanto ao tamanho de alelos em pares de bases por animal

\begin{tabular}{ccccccccc}
\hline Animal & CRD 247 & HSC & MAF 214 & OarAE 129 & OarFCB 304 & OarCP 49 & SPS 113 & D5S2 \\
\hline 1 & $229-229$ & $280-280$ & $192-209$ & $148-150$ & $165-172$ & $86-94$ & $145-147$ & $190-190$ \\
2 & $230-232$ & $272-278$ & $194-231$ & $148-148$ & $165-178$ & $92-94$ & $147-147$ & $190-193$ \\
3 & $219-229$ & $272-272$ & $194-229$ & $137-150$ & $165-172$ & $85-94$ & $138-138$ & $192-192$ \\
4 & $232-234$ & $276-290$ & $192-233$ & $148-150$ & $165-172$ & $85-100$ & $138-146$ & $192-192$ \\
5 & $232-232$ & $276-280$ & $183-227$ & $148-150$ & $149-172$ & $96-103$ & $138-146$ & $192-194$ \\
6 & $228-228$ & $285-285$ & $192-194$ & $137-144$ & $165-172$ & $85-100$ & $141-141$ & $190-192$ \\
7 & $229-244$ & $272-274$ & $192-227$ & $138-151$ & $165-165$ & $87-104$ & $147-147$ & $192-192$ \\
8 & $230-243$ & $272-276$ & $186-192$ & $148-150$ & $178-188$ & $96-119$ & $138-142$ & $192-194$ \\
9 & $241-243$ & $278-278$ & $192-203$ & $148-148$ & $165-177$ & $86-94$ & $145-147$ & $192-196$ \\
10 & $229-236$ & $276-276$ & $192-229$ & $148-150$ & $161-163$ & $85-85$ & $138-142$ & $190-193$ \\
\hline
\end{tabular}

No presente estudo foi possível observar a potencialidade da técnica em realizar a discriminação alélica para indivíduo que possui variação alélica com diferença de dois pares de bases, como exemplo o indivíduo 2, para os loci CRD247 e OarCP 49.

O número de alelos por locus variou de 5 a 10 , com média de alelos de 7.75 entre os marcadores. Para o locus MAF 214, onde os valores de PIC foram altos (PIC 86\%) foram determinados valores de 0.83 para heterozigosidade esperada e 1.00 de heterozigosidade observada. E, para o locus HSC os valores de PIC foram menores (PIC $59 \%$ ), sendo obtidos valores de 0.83 para heterozigosidade esperada e 0.40 de heterozigosidade observada (Tabela 3 ).

O conteúdo de informação de polimorfismo (PIC) variou de $86 \%$ para o marcador MAF214 a $59 \%$ para o marcador HSC, com média de $75.25 \%$ (Tabela 3).
Tabela 3 Número de Alelos por locus (N), Heterogosidade esperada (He) e Heterozigosidade observada (Ho) e Conteúdo de informação Polimórfica (PIC) entre os 10 animais para 8 loci de microssatélites em ovinos sul-mato-grossenses

\begin{tabular}{ccccc}
\hline Locus & N & He & Ho & PIC (\%) \\
\hline CRD 247 & 10 & 0.90 & 0.70 & 84 \\
HSC & 6 & 0.83 & 0.40 & 59 \\
MAF 214 & 10 & 0.86 & 1.00 & 86 \\
OAraE 129 & 6 & 0.72 & 0.80 & 64 \\
OarFCB & 9 & 0.83 & 0.90 & 76 \\
OarCP 49 & 10 & 0.90 & 0.90 & 84 \\
SPS 113 & 6 & 0.82 & 0.60 & 75 \\
D5S2 & 5 & 0.70 & 0.60 & 74 \\
\hline
\end{tabular}

O método UPGMA é o mais simples método de construção de árvores filogenéticas. Ele foi desenvolvido para a construção de fenogramas que apresentem as similaridades fenotípicas entre OTUs (Operational Taxonomic Units, ou seja, as unidades taxonômicas que se deseja comparar), mas pode também ser utilizado para construir árvores filogenéticas se as taxas de evolução são 
aproximadamente constantes entre diferentes linhagens. O dendrograma obtido a partir dos resultados das análises dos 8 loci marcadores microssatélites em 10 animais, baseado na matriz de distância pelo método de agrupamento UPGMA, indicou coeficiente de similaridade médio de 0.72 .

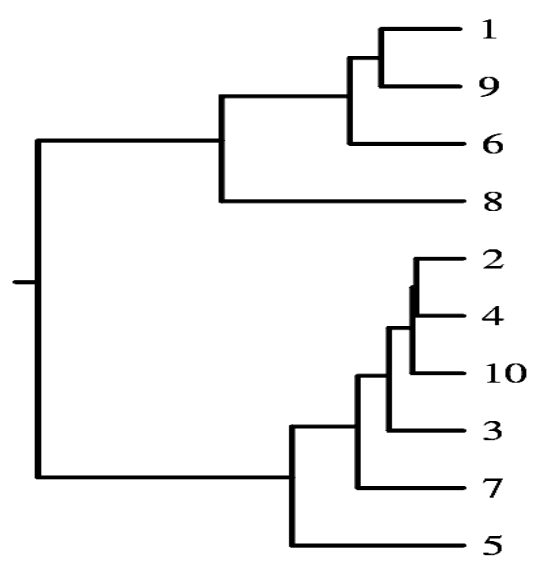

Fig 4 Dendrograma obtido pelo método de agrupamento UPGMA com base na matriz de similaridade determinada com coeficiente de Pearson para dados referentes aos 10 indivíduos genotipados da população de ovinos sul-matogrossenses, analisadas para os alelos de 8 locos microssatélites, em função das distâncias genéticas, obtidas pelo coeficiente de Nei (1972).

\section{Discussão}

A técnica de eletroforese capilar é recomendada para análises de discriminação alélica de marcadores microssatélites pelo fato de que esta possibilita a visualização de alelos mesmo quando existe pequenas diferenças em pares de bases entre produtos amplificados. Diversos trabalhos obtiveram bons resultados aplicando a técnica de eletroforese capilar para discriminação alélica de microssatélites em ovinos, tais como Kevorkian et al 2009, Arora \& Bhatia 2005, Paiva et al 2011, Almeida 2007 que realizaram estudos de caracterização de variabilidade genética e conseguiram obterem resultados satisfatórios utilizando esta técnica.

Quando os resultados da amplificação são avaliados por meio de eletroforese convencional, agarose ou nitrato de prata em alguns casos, se houver sobreposição de alelos dos marcadores, não é possível realizar testes utilizando mPCR. Como por exemplo, os marcadores OarAE 129 e SPS113 possuem fragmentos com tamanhos aproximados de 137 a $150 \mathrm{pb}$, portanto há sobreposição de alelos, não sendo possível mPCR e posterior discriminação em eletroforese de gel de agarose ou poliacrilamida. Nesse caso, como a tecnologia de eletroforese capilar utilizou os marcadores com primers foward marcados com fluoróforos (TET e FAM, respectivamente) foi possível a mPCR desses marcadores, possibilitando a leitura de ambos, mesmo possuindo tamanhos similares de produtos amplificados (Beja-Pereira \& Almeida 2005, Oliveira et al 2010). Demonstrando uma alta potencialidade no marcador para a realização estudos como variabilidade genética, caracterização de raças, estudo filogenéticos, pois mesmo com um pequeno número amostral utilizando desta tecnologia, foi possível identificar variação genética entre os mesmos para os diferentes marcadores.

Os dados relativos aos alelos identificados pela tecnologia de eletroforese capilar foram testados em programa de análise de diversidade genética, possibilitando observar que, mesmo com o pequeno número amostras testadas, observou-se 
que o número de alelos teve uma variação de $5 \mathrm{a}$ 10 alelos, indicando sua propriedade altamente mutialélica, altos valores de heterozigosidade e valores de PIC superiores a 50\% para os loci estudados corroborando com resultados obtidos por Menezes et al (2006) e Kervorkian et al (2010), que em estudos com alguns destes marcadores analisados apresentaram resultados satisfatórios para estudo de diversidade genética. Tais valores reforçam a importância de se utilizar marcadores de microssatélites, visto que, estes apresentam alta qualidade de informação que pode ser extraída para estudos diversos, tais como estudos de caracterização e diversidade genética, bem como análises de paternidade.

O dendrograma obtido pelas análises interindividuais mostraram a formação de dois clados distintos. Segundo Arranz et al (2001), esse tipo de análise é extremamente importante, pois mostra a variabilidade genética dos indivíduos sem impor a formação de grupos artificiais (ex.,famílias, grupos, populações). Tais resultados poderão ser utilizados em sistemas de cruzamentos de forma a maximizar a variabilidade genética.

A utilidade e eficência dessa técnica certamente seriam muito mais observadas se o número de animais fosse maior, onde existem perspectivas de estudos comparativos dos resultados da raça criola pantaneira com outras raças de ovinos.

Contudo, pode-se concluir que existe viabilidade e eficiência da técnica de marcadores moleculares microssatélites utilizando eletroforese capilar para discriminação alélica e a utilidade dos resultados para estudos de variabilidade genética. É importante considerar ainda que esses resultados possam servir como ferramenta para estudos de variabilidade, diagnóstico de paternidade, estudos de caracterização desse rebanho de ovinos criolos do Pantanal Sul-mato-grossense.

\section{Conflito de interesse}

Declaro que este trabalho não gera conflito de interesse de ordem: pessoal, comercial, acadêmico, político e financeiro.

\section{Agradecimentos}

A Coordenação de Aperfeiçoamento de Pessoal de Nível Superior (CAPES), à Fundação de Apoio ao Desenvolvimento do Ensino, Ciência e Tecnologia do Estado de Mato Grosso do Sul (FUNDECT) e a Universidade Federal da Grande Dourados.

\section{Literatura citada}

Almeida PAR. Diversidade genética e diferenciação das raças portuguesas de ovinos com base em marcadores de DNA microssatélites: uma perspectiva de conservação. Doutorado em Ciência Animal. Universidade Trás-os-Montes e Alto Douro, Vila Real. 2007; 333pp.

Arora R, Bhatia S. Genetic diversity of Magra sheep from India using microsatellite analysis. Asian Australas. J. Anim. Sci. (in press). 2005.

Arranz JJ, Bayón Y, San Primitivo F. Differentiation among Spanish sheep breeds using microsatellites. Genet Sel Evol. 2001; 33:529-42.

Beaumont M, Bruford MW. Microsatellites in conservation genetics. In: Goldstein DB, Schlo“ tterer C (eds) Microsatellites. New York 
(NY): Evolution and Applications Oxford University Press. 1999; 165-182.

Beja-Pereira A, Almeida NF. Genética, Biotecnologia e Agricultura. $1^{\mathrm{a}}$ ed. Porto (PT):

Sociedade Portuguesa de Inovação. 2005; 96pp.

FAO. Molecular genetic characterization of animal genetic resources. FAO Animal Production and Health Guidelines. Rome. 2011; 9:72-73.

Ferreira ME, Grattapaglia D. Introdução ao uso de marcadores moleculares em análise genética. 3ed. Brasília(BR):Embrapa-Cenargen; 1998; 220pp.

Gao LL, Anderson JP, Klingler JP, Nair RM, Edwards OR, Singh KB. Involvement of the octadecanoid pathway in bluegreen aphid resistance in Medicago truncatula. Mol Plant Microbe Interact. 2007; 20:82-93.

Garcia-Vallvé S, Puigbo P. DendroUPGMA: A dendrogram construction utility. Universitat Rovira i Virgili (URV). Tarragona. Spain. 2009.

Kashyap VK, Sitalaximi T, Chattopadhyay P, Trivedi R. DNA Profiling Technologies in Forensic Analysis. Int. J. Hum. Genet. 2004; 4(1):11-30.

Kevorkian SEM, Georgescu SE, Manea MA, Zaulet M, Hermenean AO, Costache M. Genetic diversity using microsatellite markers in four Romanian autochthonous sheep breeds. Rom Biotech Lett. 2010; 15(1):5059-65.

Kevorkian SEM, Manea MA, Gavrila MG, Rebedea M, Georgescu SE, Costache M. Sequencing of exon three of $\alpha \mathrm{S} 1$-casein sheep and goat gene. Archiva Zootechnica. 2009;12(3):87-92.
Marshall TC, Slate J, Kruuk L, Pemberton JM. Statistical confidence for likelihood-based paternity inference in natural populations. Mol Ecol. 1998; 7:639-55.

Menezes AC, Araujo HFP, Nascimento JLX, Rego ACG, Paiva AA, Serafim RN, et al. Monitoramento da população de Anodorhynchus leari (Bonaparte, 1856) (Psittacidae) na natureza. Ornithologia. 2006; 1:105-67.

Nei M. Genetic distance between populations. American Naturalist. 1972; 949:283-292.

Oliveira TS, Hoffmann LV, Alves PF, Lucena VS, Filho JLS. Validação de métodos laboratoriais aplicadas a análises com marcadores microssatélites. Revista Ciência Agronômica. 2010; 41(2):279-84.

Paiva SR, Facó O, Faria DA, Lacerda T, Barretto GB, Carneiro PL, Lobo RN, McManus C. Molecular and pedigree analysis applied to conservation of animal genetic resources: the case of Brazilian Somali hair sheep. Trop. Anim. Health Prod. 2011; 43:1449-57.

Pena LS. Frequência Alélica de 14 locos do cromossomo $\mathrm{X}$ de indivíduos da região sul do Brasil. Dissertação de Mestrado. Mestrado em Ciências Médicas - UFGRS. 2010; 94pp.

Tang WM, To KY. Four X-chromosomal STRs and their allele frequencies in a Chinese population. Forensic Sci Int. 2006; 162(13):64-5.

Voet D, Voet JG, Pratt CW. Fundamentos de Bioquímica. Porto Alegre: Artmed. 2002; $931 \mathrm{p}$. 